\title{
28 Research Square \\ Cement Dust Effect from Bokajan Cement Factory on Residents of Vicinity Area: A Study in Assam, India
}

\section{Darshana Chetia}

Community of Science Inc

Bijoylaxmi Bhuyan ( $\boldsymbol{\sim}$ bijoylaxmi_b@rediffmail.com )

Assam Agricultural University Faculty of Home Science https://orcid.org/0000-0002-2649-8973

\section{Research Article}

Keywords: Cement industry, cement dust, affect of cement dust, accumulation of dust, performance, wellbeing, safety

Posted Date: January 3rd, 2022

DOI: https://doi.org/10.21203/rs.3.rs-1045701/v1

License: (c) (i) This work is licensed under a Creative Commons Attribution 4.0 International License.

Read Full License 


\section{Abstract}

Cement manufacturing industries are one of the most common reasons of air pollution, surface and ground water pollution and noise pollution and is also indirectly affecting the people residing near the cement plants. This study was carried out to quantify the cement dust emission from Bokajan Cement Corporation of India's cement factory falling on the residences and to determine its effect on some selected household activities and general well-being of the people residing near it. An experimental method was carried out to estimate the accumulated cement dust in households. The findings showed that household activities performed by the residence were dependent upon the dust exposure, which means more the dusts are more are the cleaning and maintenance. It was also found that cement dust highly affected general wellbeing of the respondents living in southern direction and lowest affect was observed among the respondents of the east direction.

\section{Introduction}

The Bokajan Cement Plant of $\mathrm{CCl}$ is around 350 kilometres from the city of Guwahati and around 21 kilometres from the Dimapur Airport. Annually, the plant produces around 1,98,000 MT per year by using the dry process of manufacturing. The area composed of the factory, the mining area and the township. Bokajan Cement Corporation of India (C.C.I) factory is one of the 3 functional units of a total number of 10 units of cement industries in India, which is fully owned by the Central Government of India. The date of commencement of production was $1^{\text {st }}$ April, 1977. Fresh air is vital to maintain the balance of life on this planet. However, to sustain a healthy life in a healthy environment is becoming ever more tough because of pollutants emitted from different industries, power plants, agricultural activities, transportation, fuel burning, stone grinding factories, and natural phenomenon (Darçın, 2017; Sharma et al. 2002). Being the widely used component in building construction, cement manufacturing industries are one of the most common reason of air pollution, surface and ground water pollution and noise pollution and thus continuously destroying the resources by polluting the environment. The European Environment Agency, 2013, defines air pollution as "the presence of contaminants or pollutant substances in the air at a concentration that interferes with human health or welfare, or produces other harmful environmental effects". Air pollution according to the Florida Administrative Code, 1982, is the presence of any one or more substances or pollutants in quantities which are or may be harmful or injurious to human health or welfare, animal or plant life, or property, or unreasonably interfere with the enjoyment of life or property including outdoor recreation. The process of cement manufacturing emits various types of hazardous substances such as particulate matters, Sulphur oxide, Nitrogen oxide and Carbon dioxide along with heavy metals like nickel, cobalt, lead, chromium, etc. (Baby et al. 2008). These environmental devastations have significant consequence on and health of the workers working in the factory as well as the communities who reside nearby cement industries (Afolabi et al. 2012). According to Abdul-Wahab,2006 and Chukwu, 2016, in different stages of cement production, there is release of dust. Due to this dust pollution many pollutions related diseases such as cardio-vascular diseases, pulmonary diseases, gastrointestinal diseases, skin diseases, hair fall, eye problems etc and many more 
continue to increase at a frightening rate that affects quality of life (Mehraj et al. 2013; Meoet al., 2013; Adak et al., 2007; Tajudeen et al. 2011). In a study by Yhdego 1992, it was revealed that a higher percentage of related diseases occurred near the source of pollutant.

It is a universal fact that frequently occurred health problems can cause clear impact on family's monthly income and eventually happiness. Mwai and Muriithi (2016), found that Non-Communicable Diseases (NCD) have more severe impact on household income and can reduce it by 28.64 percent. In India approximately 73 million working days are lost each year due to waterborne disease (Pathak, 2015). Besides, Adekunle and team (2015) analysed the effect of cement externalities on technical efficiency of cassava-based farmers in Ogun State, Nigeria and concluded that there was a negative impact of cement emission on the work efficiency of the people residing near the cement factory. As a significant risk factor, air pollution affects general well-being of people who are continuously exposed to the pollutants. In a study of Murat Darcin $(2014 ; 2017)$ it was found that good air quality is significant to people's quality of life, happiness, life satisfaction, and optimistic view. Arif and team (2016), stated that the relation between well-being and air quality is one of the essential issues in public policy designing. $\mathrm{Ng}$ and Fisher (2013) were concerned about the well- being of an individual as a critical issue for the societal development. Wellbeing of every individual is very important for the well being of the society and the nation at large. Thus, this study was aimed at to understand if dust emission from Bokajan CCl cement factory had any effect on normal life of people residing in the vicinity with the following objectives.

i. To estimate the quantity of cement dust accumulation in the vicinity area.

ii. To observe the effect of cement dust on selected household activities in the vicinity area.

iii. To determine the effect of cement dust on general well being of the selected community.

Null Hypothesis: Performance of the respondents of the vicinity area is independent of the exposure to dust.

\section{Operational Definitions:}

i. Effect: In this study effect refers to direct or indirect influence of cement dust exposure on human health and performance.

ii. Performance: Performance in the study refers to accomplishment of household work by people in the vicinity area with respect to pre-set standards.

iii. Wellbeing: The general wellbeing here refers to the condition of good health and its influence on family, social satisfaction, a sense of accomplishment and personal fulfilment.

\section{Methodology}

\section{Selection of the sample for selected household activity and general well being:}


In order to undertake the samples for the present study, a total of 100 households ( 25 from each direction) were randomly selected from the vicinity area of $2 \mathrm{~km}$ radius from the $\mathrm{CCl}$ factory, Bokajan, with respect to four directions i.e.,East, West, North and South surrounding the factory. A total of 25 respondents from each household were selected from each direction making a total of 100 numbers of respondents.

\section{Estimation of accumulated dust:}

In order to estimate the accumulation of dust from Bokajan $\mathrm{CCl}$ factory, in the vicinity area an experimental method was carried out. Four equal sized cardboard boxes with a removable good quality glossy finished white sheet of paper of 1 sq.ft in size were placed in an open space (plate I) in the houses of four respondent's located in four directions i.e. east, west, north and south which were equidistant from the factory. All the boxes were placed in that specific location once for 24 hours every month on the same day from January 2017 to December 2017. After 24 hours the accumulated cement dusts were collected taking utmost care that dust particles do not remain stuck on the paper. Collected dusts were carefully packaged in small plastic pouches and were properly sealed. After this process, dusts were measured and quantified in a Digital Gold Weighing machine with the measuring calibration of $0.01 \mathrm{~g}$ to $500 \mathrm{~g}$ scale (plate II).

\section{Method of data collection:}

To find out the effect of cement dust in household activities and general wellbeing an interview cum observation method was implemented using structured questionnaire on 100 respondents from the aforesaid households selected. Data was collected using a pre-tested structured schedule personally by the researcher with a care to note only reliable and valid information. Analysis of data to observe the effect of cement dust in household activities was done in three point scale statements and recorded the responses as "Always", "Sometimes" and "Never" with corresponding scores of 3,2,1. Similarly, to determine the effect of cement dust on general wellbeing of the residents information were collected on the basis of five point rated statements and recorded the responses as "Strongly agree", "Agree", "Neutral", "Disagree", and "Strongly disagree" with corresponding scores of 5,4,3,2,1.

\section{Statistical analysis:}

On the basis of scores obtained to see the effect of cement dust in household activities and general wellbeing of the respondents Mean \pm S.D is computed and categorized into three groups i.e., highly effected, moderately effected and less affected.
a. Score $>$ Mean + S.D
Highly effected
b. Score in between Mean + S.D and Mean - S.D
Moderately effected
c. Score < Mean - S.D
Less effected 
The performance of household activities were categorised into three categories in percent from a list of fourteen numbers of commonly done household activities related to upkeep of the house as follows.

\begin{tabular}{|ll|}
\hline Categories & Amount of household activities \\
\hline a. High & $>75$ \\
\hline b. Medium & $50-75$ \\
\hline c. Low & $<50$ \\
\hline
\end{tabular}

Chi square test was used to find out the association between accumulation rate of cement dust and performance of the respondents and also between accumulation rate of cement dust and general wellbeing of the vicinity area.

\section{Results And Discussion}

\section{Quantification of Accumulated Dust (Wt. in mg) From CCI Cement Factory, Bokajan in Residential Areas in Terms of Location}

In order to estimate the quantity of accumulated dust from Bokajan CCl factory on the houses of the vicinity area direct measure of the dusts were done using an experimental method as mentioned above. The collected dusts were measured and quantified and presented in the Table 1. 
Table 1

Quantification of accumulated dust in terms of weight from Bokajan cement factory in the vicinity area with respect to direction

\begin{tabular}{|lllll|}
\hline Months & $\begin{array}{l}\text { East } \\
\text { (wt. in mg) }\end{array}$ & $\begin{array}{l}\text { West } \\
\text { (wt. in } \mathbf{~ m g )}\end{array}$ & $\begin{array}{l}\text { North } \\
\text { (wt. in } \mathbf{~ m g})\end{array}$ & $\begin{array}{l}\text { South } \\
\text { (wt. in mg) }\end{array}$ \\
\hline January, 2017 & 120 & 190 & 280 & 350 \\
\hline February, 2017 & 130 & 280 & 350 & 400 \\
\hline March, 2017 & 170 & 290 & 360 & 420 \\
\hline April, 2017 & 110 & 290 & 350 & 400 \\
\hline May, 2017 & 95 & 200 & 270 & 370 \\
\hline June, 2017 & 90 & 200 & 260 & 340 \\
\hline July, 2017 & 80 & 180 & 250 & 320 \\
\hline August, 2017 & 90 & 190 & 270 & 360 \\
\hline September, 2107 & 90 & 200 & 280 & 360 \\
\hline October, 2017 & 100 & 210 & 250 & 385 \\
\hline November, 2017 & 110 & 250 & 310 & 395 \\
\hline December, 2017 & 90 & 200 & 290 & 360 \\
\hline Total (wt in mg) & 1275 & 2680 & 3530 & 4460 \\
\hline
\end{tabular}

Data represented in Table 1 showed that dust accumulation rate was highest in south direction and lowest in east. It might be due to wind blowing direction as blowing of wind in this direction is more. It was also found that dust accumulation rate was higher in the months of February, March and April which could be due to more wind and comparatively low in the months of June, July and August that might be due to more rain. It was observed during the investigation that residential area in southern direction followed by northern direction was heavily covered with cement dust including vegetation, roof coverings, houses, roads etc. compared to other sides.

\section{Effect of Cement Dust on Household Activities of The Residents in The Vicinity Area}

Data in Table 5 represents the opinions of the respondents regarding effect of cement dust in their household activities related to cleaning and up keeping of the house (appendix I). The calculated scores based on the opinions of respondents of four directions indicated high level of effect of cement dust on 
household activities of the respondents of south direction (high-32\%, medium-56\% and low- $12 \%$ ) compared to other direction. It was observed that lowest effect was found among the respondents of the east direction (high- $0 \%$ medium- $64 \%$ and low-36\%). In this context it can be said that respondents of the south direction faced more problems to finish their household tasks due to more dust accumulation compared to east direction which was also observed personally by the investigator during the course of the study. As reported by the respondents when the factory remains active during manufacturing process dust particles were found everywhere in the house making the utensils, clothes, TV, furniture, furnishings, railings, cars, etc dirty. Everything used to be covered with powdery dust layers requiring constant cleaning and washing that led to difficulty in time management and affects other constructive supplementary income generating activities and personal care of the homemakers.

Table 2. Distribution of the respondents according to the effect of cement dust on household activities of the respondents in vicinity area according to four directions $(\mathrm{N}=100)$

\begin{tabular}{llll}
\hline Direction & $\begin{array}{l}\text { Category } \\
\text { (Level of effect) }\end{array}$ & Frequency & Percentage \\
\hline East & High (above 35.04) & - & - \\
& Medium (19.03-35.04) & 16 & 64 \\
& Low (below 19.03) & 9 & 36 \\
West & High (above 32.86) & - & - \\
& Medium (29.05-32.86) & 21 & 84 \\
& Low (below 29.05) & 4 & 16 \\
North & High (above 34.28) & 6 & 24 \\
& Medium (20.11-34.28) & 13 & 52 \\
& Low (below 20.11) & 6 & 24 \\
\multirow{3}{*}{ South } & High (above 31.78) & 8 & 32 \\
& Medium (18.45-31.78) & 14 & 56 \\
& Low (below 18.45) & 3 & 12 \\
\hline
\end{tabular}

\section{Association between exposure to cement dust and its effect on performance of household activities in terms of direction}

In the aforesaid discussion in Table 1 it was established that dust accumulation rate was high in south direction and lower in east direction. In this context this part of the study attempted to find out the association between accumulation rate of cement dust and its effect on household performance of the respondents of the vicinity area of the cement factory in terms of four directions. 
Null hypothesis $\left(\mathrm{H}_{0}\right)=$ Performance of the respondents of the vicinity area is independent upon the exposure to dust.

Table 3

Distributions of respondents according to the amount of household activities needed to be performed in terms of direction

\begin{tabular}{|llllll|}
\hline Observed category & \multicolumn{5}{c|}{ Observed value with respect to directions } \\
\cline { 2 - 6 } & South & North & West & East & Total \\
\hline High $(<75 \%)$ & 14 & 10 & 7 & 3 & 34 \\
\hline Medium $(50 \%-75 \%)$ & 8 & 10 & 10 & 9 & 37 \\
\hline Low $(>50 \%)$ & 3 & 5 & 8 & 13 & 29 \\
\hline Total & 25 & 25 & 25 & 25 & 100 \\
\hline
\end{tabular}

Table 4

Chi square value showing the association between exposure to dust and amount of household activities needed to be performed

\begin{tabular}{|lll|}
\hline Dependent variable & Independent variable & $\begin{array}{c}\text { Chi square } \\
\text { value }\end{array}$ \\
\hline $\begin{array}{l}\text { Amount of household activities performed for upkeep of } \\
\text { their residences }\end{array}$ & $\begin{array}{l}\text { Cement dust } \\
\text { accumulation rate }\end{array}$ & $15.71^{*}$ \\
\hline *Significant at 5 per cent probability level & & \\
\hline
\end{tabular}

Degrees of freedom $(\mathrm{d} . \mathrm{f})=($ number of rows -1$)($ number of column -1$)=6$

Table value for 6 degrees of freedom is 12.59. The calculate value (15.71) is greater than the table value hence can be said as significant. Therefore, we reject the null hypothesis and we conclude that the amount of household activities performed for upkeep of their residence was dependent upon the dust exposure.

\section{Effect of cement dust on general wellbeing of the residents in the vicinity area}

Effect of cement dust on general wellbeing of the residence in the vicinity area of the cement factory was studied in terms of four different directions. Scores were calculated on the basis of respondent's opinion regarding effects of cement dust on their household environment, workspace and family budget. Most of the respondents reported that flowers and foliages, greens and vegetables don't grow well in their kitchen gardens due to dust covering on the entire leaf surfaces and the plant body as a result people had to entirely depend on market which added to their family budget (Plate 1). Similar studies of effect of 
cement dust on vegetation was reported by Ramanathan et al. (2006),Raajasubramanianet al. (2011), Oran and Zahra (2014), Rawat and Katiyar (2015), Romman and Alzubi (2015), Senthil et al. (2015).Results depicted in Table 5 reveals that level of effect of cement dust on general wellbeing of respondents living in southern direction was high (high-20\%, medium- $68 \%$ and low-12\%). Lowest effect was observed among the respondents of the east direction (high- $0 \%$ medium- $76 \%$ and low- $24 \%$ ).

Table 5. Distribution of the respondents according to the effect of cement dust on general wellbeing of respondents living in the vicinity area with respect to direction

$(\mathrm{N}=100)$

\begin{tabular}{|l|l|l|l|}
\hline Direction & Category (level of effect) & Frequency & Percent \\
\hline \multirow{5}{*}{ East } & High (above 25.09) & - & - \\
\cline { 2 - 4 } & Medium (19.70-25.09) & 19 & 76 \\
\cline { 2 - 4 } & Low (below 19.70) & 6 & 24 \\
\hline \multirow{5}{*}{ West } & High (above 40.03) & - & \\
\cline { 2 - 4 } & Medium (32.20-40.03) & 23 & 92 \\
\cline { 2 - 4 } & Low (below 32.20) & 2 & 8 \\
\hline \multirow{5}{*}{ South } & High (above 26.55) & 4 & 16 \\
\cline { 2 - 4 } & Medium (18.88-26.55) & 16 & 64 \\
\cline { 2 - 4 } & Low (below 18.88) & 5 & 20 \\
\cline { 2 - 4 } & High (above 27.47) & 5 & 68 \\
\cline { 2 - 4 } & Medium (20.44-27.47) & 3 & 12 \\
\cline { 2 - 4 } & Low (below 20.44) & & \\
\hline
\end{tabular}

\section{Summary And Conclusion}

In the present study it was observed that the vicinity area of the cement factory was badly affected by cement dust. The area was observed to be coated by a layer of cement dust including the trees, roads, ponds, dwellings etc. The greenery of vegetation of the surrounding area was affected which caused direct or indirect impact on public lives. The afore mentioned discussion established that the people residing on the south and north direction were exposed to higher amount of cement dust emission and it had negative effect on their household activities and general wellbeing. This study recommends planting more trees around the compound of the residents for providing barrier to cement dust from entering into the houses possibly to certain extent. Planning of industries should be done according to wind flow direction of the location or the residential areas should be planned in the area where wind blowing is less. Since cement dust is always emitted from the Bokajan CCl cement factory, considerable effort must also be directed towards preventing particulates from going into the atmosphere, as its effect is unpredictable in the environment, special devices to arrest and mop up particulates should be provided and adequate steps should be taken to keep it functional by the factory authority. The public relation officers should monitor any affect in the residences of vicinity area and adequate awareness should be provided to 
minimise impacts hazards of cement dust. In order to control air pollution more tall and evergreen trees should be planted around the factory and use water sprinklers from time to time to reduce dust in the area. Protective measures if taken adequately has multifaceted impacts- good for the environment and ecosystem nearby, good to the inhabitants and good to the industry to economically prosper and remain sustainable for long years to come.

\section{Declarations}

\section{I hereby declare the following-}

1. "I have not submitted my manuscript to a preprint server before submitting it to Environmental Science and Pollution Research".

2. 'Declarations': 'Not applicable'

\section{Others}

- Ethics approval and consent to participate 'Not applicable'

- Consent for publication 'Not applicable'

- Availability of data and materials 'Not applicable'

- Competing interests 'Not applicable'

- Funding 'Not applicable'

- Authors' contributions 'Not applicable'

- Acknowledgements 'Not applicable'

- Authors' information (optional) 'Not applicable'

\section{Ethics approval and consent to participate "Not applicable". \\ 5. Consent for publication "Not applicable"}

\section{All data generated or analysed during this study are included in this published article [and its supplementary information files].}

\section{Funding: "Not applicable" (As it is student's M.Sc thesis work).}

\section{Acknowledgments "Not applicable"}

\section{References}

1. Abdul-Wahab SA (2006) Impact of fugitive dust emissions from cement plants on nearby communities. Ecol Modell 195:338-348

2. Adak MD, Adak S, Purohit KM (2007) Ambient air quality and health hazards near mini cement plants. Pollution Research 26(3):361-364 
3. Afolabi A, Francis FA, Adejompo F (2012) Assessment of health and environmental challenges of cement factory on Ewekoro community residents, Ogun state, Nigeria. American Journal of Human Ecology 1(2):51-57

4. Arif M, Katafygiotou M, Mazroei A, Kaushik A, Elsarrag E (2016) Impact of indoor environmental quality on occupant well-being and comfort: A review of the literature. International Journal of Sustainable Built Environment 5(1):1-11

5. Baby S, Singh NA, Shrivastava P, Nath SR et al (2008) Impact of dust emission on plant vegetation of vicinity of cement plant. Environ Eng Manag J 7(1):31-35

6. Darçın M (2014) Association between air quality and quality of life. Environ Sci Pollut Res 21(3):1954-1959

7. Darçın M (2017) How air pollution affects subjective well-being. Medical Perspective, Well-being and Quality of Life, p 211

8. European Environment Agency (2013) Environmental Terminology and Discovery Service (ETDS)

9. Mehraj SS, Bhat GA, Balkhi HM (2013) Cement factories and human health. International Journal of Current Research and Review 5(18):47-53

10. Meo SA, Al-Drees AM, Masri AAA, Rouq FA, Azeem MA (2013) Effect of duration of exposure to cement dust on respiratory function of non-smoking cement mill workers. Int $\mathrm{J}$ Environ Res Public Health 10:390-398

11. Ubosi MN NI (2016) Impact of cement dust pollution on respiratory systems of Lafarge cement workers, Ewekoro, Ogun State, Nigeria. Glob J Pure Appl Sci 22:1-5

12. Mwai D, Muriithi M (2016) Economic effects of non-communicable diseases on household income in Kenya: a comparative analysis perspective. Public Health Res 6(3):83-90

13. Ng ECW, Fisher AT (2013) Understanding well-being in multi-levels: a review. Health, Culture and Society 5(1):308-323

14. Oran SA, Zahra HMFA (2014) Impact of the cement dust emitted from the South Cement Factory in Tafila/ Jordan on plant diversity of the surrounding area. International Journal of Biodiversity and Conservation 6(5):400-414

15. Pathak H (2015) Effect of water borne diseases on Indian economy: a cost-benefit analysis. An Rom Sov Ser Med Gen 1:74-78

16. Raajasubramanian D, Sundaramoorthy $P$ et al (2011) Effect of cement dust pollution on germination and growth of groundnut (Arachis hypogaeaL.). International Multidisciplinary Research Journal 1(1):25-30

17. Ramanathan R, Jeyakavitha $T$, Jeganathan M (2006) Impact of cement dust on Azadirachta indica leaves - A measure of air pollution in and around Ariyalur. J Ind Pollut Control 22(2):273-276

18. Rawat V, Katiyar R (2015) A review on the effects of cement dust on vegetation. International Journal of Scientific \& Innovative Research Studies 3(4):39-45 
19. Romman SA, Alzubi J (2015) Effects of cement dust on the physiological activities of Arabidopsis thaliana. American Journal of Agricultural and Biological Sciencesica 10(4):157-164

20. Senthil KP, Sobana K, Kavitha KK, Jegadeesan M (2015) A study on the effect of cement dust pollution on certain physical and biological parameters of Sessamum indicumplant. Asian Journal of Plant Science and Research 5(1):1-3

21. Sharma T, Rainey RC, Neumann CM et al (2002) Roadside particulate levels at 30 locations in the Kathmandu Valley, Nepal. Int J Environ Pollut 17(4):293-305

22. Tajudeen Y, Okpuzor J, Fausat AT (2011) Investigation of general effects of cement dust to clear the controversy surrounding its toxicity. Asian Journal of Scientific Research 4(4):315-325

23. Yhdego M (1992) Epidemiology of industrial environmental health in Tanzania. Environ Int 18(4):381-387

\section{Appendix}

Appendix 1 is not available with this version

\section{Figures}

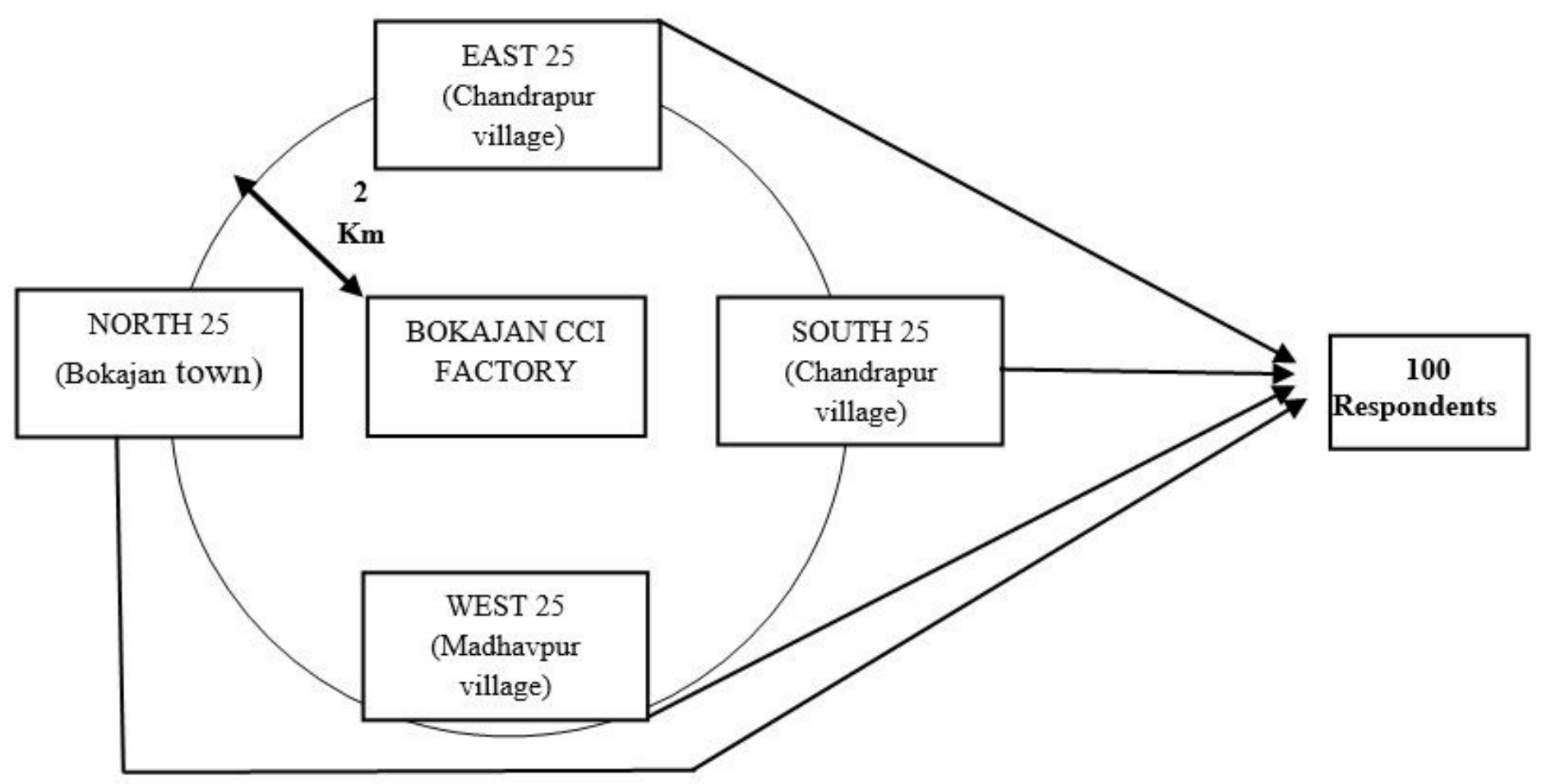

Figure 1

Diagrammatic representation of selection of non-worker samples 


\section{Supplementary Files}

This is a list of supplementary files associated with this preprint. Click to download.

- Supplementallmages.docx 